\title{
Construção de um biodigestor: uma proposta de ensino interdisciplinar para escolas do campo
}

\author{
The construction of a biodigester: an interdisciplinary teaching \\ approach for rural schools
}

\author{
Fernanda Teresa Moro (fernanda.moro@uffs.edu.br) \\ Professora Substituta da Universidade Federal da Fronteira Sul (UFFS), Campus de Erechim - RS \\ Eliseu Paulo Coppi (coppieliseu@gmail.com) \\ Rede Estadual de Educação - Itatiba do Sul - RS \\ Moises Marques Prsybyciem (moises.prsybyciem@uffs.edu.br) \\ Universidade Federal da Fronteira Sul (UFFS), Campus de Erechim - RS
}

\begin{abstract}
Resumo: Este trabalho apresenta um relato de experiência desenvolvido por um professor da Educação Básica, com estudantes do $2^{\circ}$ ano do Ensino Médio de uma escola estadual de Itatiba do Sul, Rio Grande do Sul. O objetivo do trabalho foi desenvolver uma proposta que contemplasse conteúdos estudados em sala de aula e sua aplicabilidade, propondo melhorias à comunidade escolar. A proposta didática envolveu a construção de um biodigestor para o aproveitamento dos resíduos da comunidade escolar na produção de energia e a fabricação de um biofertilizante. Com base no pressuposto de que a educação constrói-se no meio em que se vive, com os seus desafios e possibilidades, espera-se que os estudantes sejam protagonistas de mudanças e que a escola seja um espaço aberto à construção de saberes, buscando uma formação integral e dando sentido aos conteúdos trabalhados. O trabalho proposto possibilitou aos estudantes ir além dos conteúdos específicos do currículo escolar, permitindo a integração entre as disciplinas de Biologia, Física e Química e visando a alternativas sustentáveis, mostrando que o ensino não precisa estar centrado na linearidade dos conteúdos apresentada nos livros didáticos.
\end{abstract}

Palavras-chave: Biodigestor; Ciências da Natureza; Interdisciplinaridade; CTS.

\begin{abstract}
This paper aims to present an experience-based report carried out by an elementary school teacher along with $12^{\text {th }}$ graders of a state school in Itatiba do Sul, Rio Grande do Sul. It addresses a teaching proposal that contemplates contents studied in the classroom and its practice, suggesting improvements to the school community. The didactics in this study was applied in the construction of a biodigester, which uses waste from the local community for the generation of energy and bio fertilizer. Based on the assumption that education takes place anywhere, with challenges and possibilities, students are expected to have the main role for world changes, and the school must be the place where knowledge is promoted, through an educational system that covers all aspects of human development with meaningful contents. Thus, the present study enabled students to go beyond specific school contents, integrating subjects such as
\end{abstract}


Biology, Physics and Chemistry as well as fostering sustainable alternatives. It shows that teaching transcends book-centered activities.

Key words: Biodigester; Natural Sciences; Interdisciplinarity; CTS.

\section{INTRODUÇÃO}

A preocupação com a questão ecológica, ambiental e de saúde pública tem sido tema de debates e propostas investigativas na atualidade, e essas questões não podem deixar de perpassar o trabalho educativo. Ao pensar propostas no enfoque da Ciência, Tecnologia e Sociedade (CTS) para o ensino das Ciências, na Educação do Campo, busca-se, além do conhecimento científico, uma aprendizagem sobre a Ciência frente à evolução tecnológica e em prol de melhorias e avanços econômicos e sociais, principalmente para as comunidades em que as escolas de campo estão inseridas. É necessário, por um lado, compreender os fatores que limitam e impossibilitam avanços e melhorias, que dificultam a implementação de novas técnicas, e, por outro lado, visualizar possibilidades para o reaproveitamento dos resíduos oriundos de diferentes setores, como agricultura, pecuária, suinocultura, entre outros.

Este trabalho apresenta os resultados de uma proposta didática desenvolvida por um professor da Educação Básica em uma escola de Campo, no interior do município de Itatiba do Sul, Rio Grande do Sul. Considerando que a escola em que esta investigação foi aplicada já possui uma horta escolar, esta proposta visa a uma construção conjunta de um biodigestor, possibilitando aos estudantes novos olhares frentes às práticas de manejo e cuidado com o solo, no intuito de revitalizar a horta escolar, inserindo questões agroecológicas de produção, priorizando a qualidade do alimento produzido - sem a utilização de agrotóxicos -, bem como o aproveitamento da energia gerada na decomposição de resíduos, sejam eles de origem vegetal ou animal.

Como objetivos centrais desta proposta, buscou-se: a) identificar as concepções iniciais dos estudantes sobre o tema "agrotóxicos e energias renováveis"; b) desenvolver uma proposta didática com os estudantes sobre o tema "agrotóxicos" na perspectiva da Agroecologia e com enfoque em CTS para o ensino de Ciências da Natureza; c) revitalizar a horta escolar, promovendo a utilização de bioinseticidas e biofertilizantes; e 
d) construir um biodigestor em conjunto com os estudantes, para a produção de biogás e biofertilizante.

Frente às inúmeras demandas e possibilidades de tornar a escola um local que propicie conhecer a aplicabilidade dos conteúdos estudados, onde o desafio diário está em tornar a prática e a construção conjuntas - ferramentas que abarcam o verdadeiro conhecimento -, este trabalho traz como principal desafio apresentar para a comunidade escolar uma alternativa viável, econômica e sustentável de aproveitamento de resíduos e conscientização ecológica. Em escola de campo situada em município do interior, cada alternativa que se possa oferecer para que os estudantes sejam protagonistas de mudanças reflete-se na realidade local como possibilidade de empreendedorismo e investimento.

Preocupados com a questão ambiental e visando a alternativas sustentáveis, o plano de ação foi além da temática de currículo específico: ampliaram-se os conhecimentos, com um olhar interdisciplinar, vislumbrando perspectivas futuras para as propriedades rurais. A construção de um biodigestor tornou-se significativa no momento em que juntos, professor e estudantes, buscaram as alternativas e respostas de que precisavam: O quê? Para quê? Como? Com que materiais? Quando? Em quanto tempo? Com que objetivo? Com quais resíduos?

\section{PRESSUPOSTOS TEÓRICOS}

Muitos autores propõem que o conhecimento adquirido nas escolas com as disciplinas de Ciências da Natureza sejam incorporados enquanto cultura, a fim de permanecerem mesmo após a saída dos bancos escolares. De acordo com Delizoicov, Angotti e Pernambuco (2009, p. 69):

[...] uma das funções do ensino das Ciências nas escolas fundamental e média é aquela que permite ao aluno se apropriar da estrutura do conhecimento científico e de seu potencial explicativo e transformador, de modo que garante uma visão abrangente, quer por processos quer daqueles produtos.

Nesse sentido, a interdisciplinaridade apresenta-se como um complemento e uma abertura dialogada entre as diferentes disciplinas e as diversas temáticas estudadas, não 
se detendo somente a currículos, mas possibilitando a articulação entre os diferentes campos do conhecimento, descrevendo a realidade e desenvolvendo competências. Os Parâmetros Curriculares do Ensino Médio apontam:

\begin{abstract}
Na perspectiva escolar, a interdisciplinaridade não tem a pretensão de criar novas disciplinas ou saberes, mas de utilizar os conhecimentos de várias disciplinas para resolver um problema concreto ou compreender um determinado fenômeno sob diferentes pontos de vista. Em suma, a interdisciplinaridade tem uma função instrumental. Trata-se de recorrer a um saber diretamente útil e utilizável para responder às questões e aos problemas sociais contemporâneos. (BRASIL, 1999, p. 34).
\end{abstract}

Watha, Silva e Bejarano (2013) corroboram com esta ideia ao destacar que a contextualização no ensino é uma estratégia fundamental para a construção de significações, na medida em que incorpora relações implícitas do processo. Desde a implementação da lei de Diretrizes e Bases da Educação (LDB - 9394/96) e dos Parâmetros Curriculares Nacionais (PCNs), propostas que envolvam a contextualização e a interdisciplinaridade vêm sendo discutidas: torna-se imperativa a inserção do contexto ao Ensino de Ciências Naturais. Precisa-se dar sentido àquilo que se ensina.

No Ensino de Ciências, é importante que o professor desenvolva os conteúdos estabelecendo as relações entre Ciência, Tecnologia, Sociedade (CTS). Fabri e Silveira (2015) enfatizam que há a necessidade de uma educação científica que permita ao estudante a reflexão sobre os impactos que os avanços científicos e tecnológicos causam, transformando os saberes do senso comum em conhecimentos mais elaborados. Propostas investigativas que contemplam a abordagem CTS buscam, conforme Nascimento e Lisingen (2006), promover o interesse dos estudantes em relacionar a ciência com as aplicações tecnológicas e os fenômenos da vida cotidiana, destacando fatos e aplicações científicas que tenham uma maior relevância social.

Já Santos e Mortimer (2002) destacam que a abordagem CTS em sala de aula busca promover a alfabetização científica dos estudantes para que tenham condições de intervir de forma crítica no contexto social no qual estão inseridos, desenvolvendo conhecimentos, habilidades, atitudes e valores que possibilitem a tomada de decisão responsável e consciente sobre questões relativas à ciência e à tecnologia na sociedade. Baseado, então, nos pressupostos da abordagem CTS, pensou-se nesta proposta de intervenção didática. 
A preocupação com o destino dos resíduos orgânicos - e o seu impacto no ecossistema, flora, fauna e meio ambiente -, é o fator norteador que direciona atitudes e ações coletivas para alcançar resultados e comprometimento da sociedade. Os resíduos, geralmente de suínos, bovinos e aves, trazem várias formas de contaminação para os corpos hídricos, desequilíbrio ambiental, proliferação de insetos e gás metano, entre outros. Repensar e viabilizar maneiras de diminuir o impacto desses resíduos no ecossistema é, com certeza, uma preocupação atual. Assim, pensou-se em como aproveitar os resíduos originados na escola e a possibilidade de transformarem-se em energia e/ou biofertilizantes. A partir das considerações de Hunsche (2010), alguns objetivos do currículo CTS visam a:

[...] promover o interesse dos estudantes em relacionar ciência com as aplicações tecnológicas e os fenômenos cotidianos; abordar o estudo de fatos e aplicações científicas que tenham maior relevância social; abordar as aplicações sociais e éticas relacionadas à Ciência e Tecnologia; compreender a natureza da ciência e do trabalho científico (HUNSCHE, 2010, p. 36).

As atividades desenvolvidas e apresentadas neste relato de experiência encontraram-se em consonância com a perspectiva CTS, uma vez que buscou-se a conscientização e a apresentação de uma proposta de produção de biofertilizante com os resíduos utilizados em um biodigestor, destacando, inclusive, a possibilidade de uso do biogás produzido no biodigestor e proporcionando uma economia no gás derivado de fontes fósseis e utilizado na cozinha da escola.

\section{DESENVOLVIMENTO DA PROPOSTA}

A escola em que esta investigação foi aplicada está inserida em uma realidade que oportuniza o acesso a políticas públicas, percebendo em seus estudantes a possibilidade da emancipação do meio rural: além de formar pedagogicamente, está comprometida na construção de sujeitos protagonistas de suas histórias.

Essa escola atende um total de 240 estudantes, sendo 123 no turno da manhã, 68 no turno da tarde e 49 no turno da noite. Eles são oriundos de todas as localidades do 
município, pois a escola em questão é a única de Ensino Médio da cidade. Os estudantes são de diversas realidades socioeconômicas - sendo a maioria das classes mais carentes - e a faixa etária do corpo discente varia de 6 a 37 anos de idade. A investigação aqui relatada foi desenvolvida em uma turma do segundo ano do Ensino Médio noturno composta por 12 estudantes, todos oriundos de comunidades próximas, do interior e da cidade.

Um mini biodigestor foi construído com auxílio dos estudantes e professores com materiais recicláveis e de baixo custo para a escola. O biogás produzido pelo biodigestor é gerado com aproveitamento dos resíduos encontrados no meio rural, oportunizando economia visível e sustentabilidade ambiental, além de ser de fácil construção e, como recém-citado, de custo inicial muito baixo.

Ao planejar as atividades para a construção do biodigestor, buscou-se a interação entre conceitos de Física, Química e Biologia. Com o componente curricular da Biologia, foi abordada a fermentação, a função das bactérias na fermentação, bem como o processo envolvido nestas transformações. Também receberam atenção no estudo as fases da biodigestão anaeróbica - hidrólise, acidogênese, acetogênese e metanogênese.

Já na Química, trabalharam-se os impactos causados pelo gás metano, a conservação da massa e a composição molecular da matéria orgânica e inorgânica. Além disso, receberam ênfase as noções de fermentação e transformações na criação do gás metano, os efeitos causados por esse gás no meio ambiente - principalmente os oriundos da criação de animais - e a possibilidade de acúmulo de resíduos, contaminando a água e o solo. No entanto, os estudantes precisaram compreender que esses mesmos resíduos são excelentes matérias-primas para o biodigestor. Em contrapartida, a Física apontou as possibilidades de transformação da energia, propagação do calor, estados da matéria, termodinâmica, pressão dos gases, volume, densidade, calor, calor latente e calor específico.

Durante o desenvolvimento das aulas, surgiu a necessidade de discussão de outra temática relevante na construção do biodigestor: a Biossegurança, que compreende o conjunto de ações e medidas que se voltam para a prevenção, controle, minimização e 
eliminação de riscos provenientes do manuseio, pesquisa, produção e desenvolvimento tecnológico.

Buscou-se, no primeiro momento da intervenção pedagógica, propiciar a reflexão dos estudantes sobre a temática da construção de um biodigestor e sua utilização no espaço escolar, como é seu funcionamento, do que é feito, como ocorre o processo de produção de biogás e de biofertilizante, seu impacto na questão ambiental e no ecossistema. Em um segundo momento, a atividade proposta - e considerada desafiadora para a turma - foi a construção do biodigestor, com materiais elencados e adquiridos anteriormente. Após a construção, foi adicionada ao biodigestor a matériaprima - esterco, dejetos, restos de plantas e hortaliças - necessária para a produção do biometano. Os estudantes analisaram a forma de utilização dos rejeitos, após a fermentação, como biofertilizante para a horta escolar, que já existe na escola em que foi realizada esta investigação.

A Figura 1 ilustra o trabalho dos estudantes na construção do biodigestor.

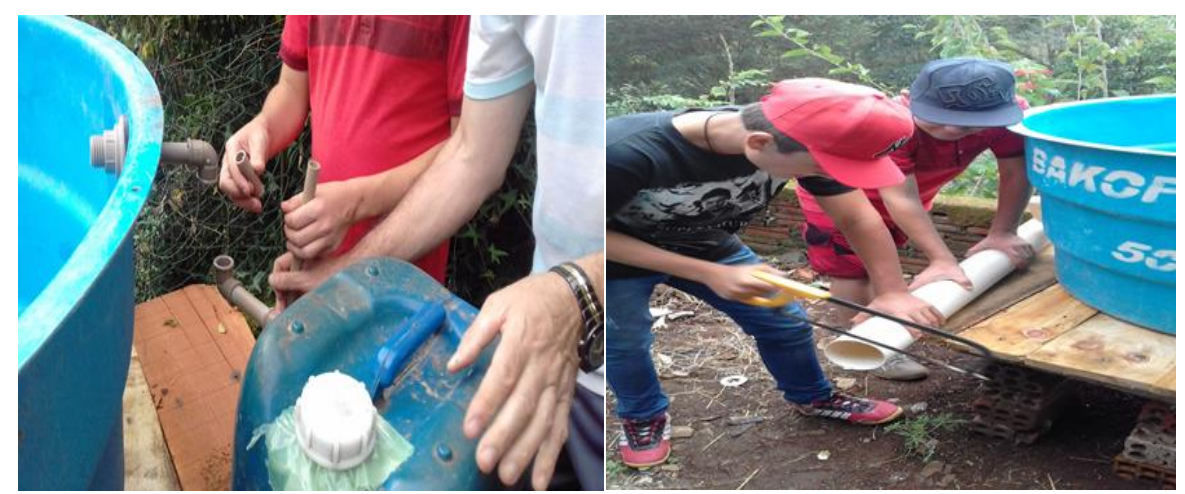

Figura 1 - Construção do Biodigestor pelos estudantes, na Escola.

Cabe destacar que ao se trabalhar a biossegurança, foram esclarecidos os riscos biológicos e físicos, os contaminantes e como as tecnologias serviram de suporte e evolução para amenizar os impactos e garantir a saúde humana e do meio ambiente. Durante a intervenção, também foram destacados tópicos como toxinas, bactérias que atuam na proliferação e fermentação do biogás, como ocorre o processo, como intensificar, que alimentos favorecem a fermentação e a produção de biogás. É 
importante salientar que a questão da temperatura foi muito discutida, tendo em vista a necessidade de aquecimento para que as bactérias trabalhassem na fermentação. Discussões a respeito das estações do ano e dos locais apropriados para a instalação do biodigestor, devido às características da região, perpassaram as atividades propostas.

Na última aula, ocorreu a testagem da produção do biogás com a observação da sua queima. Também foi proposta a elaboração de cartazes de sensibilização, envolvendo temáticas ambientais.

A Figura 2 apresenta o cartaz produzido por um grupo de estudantes.
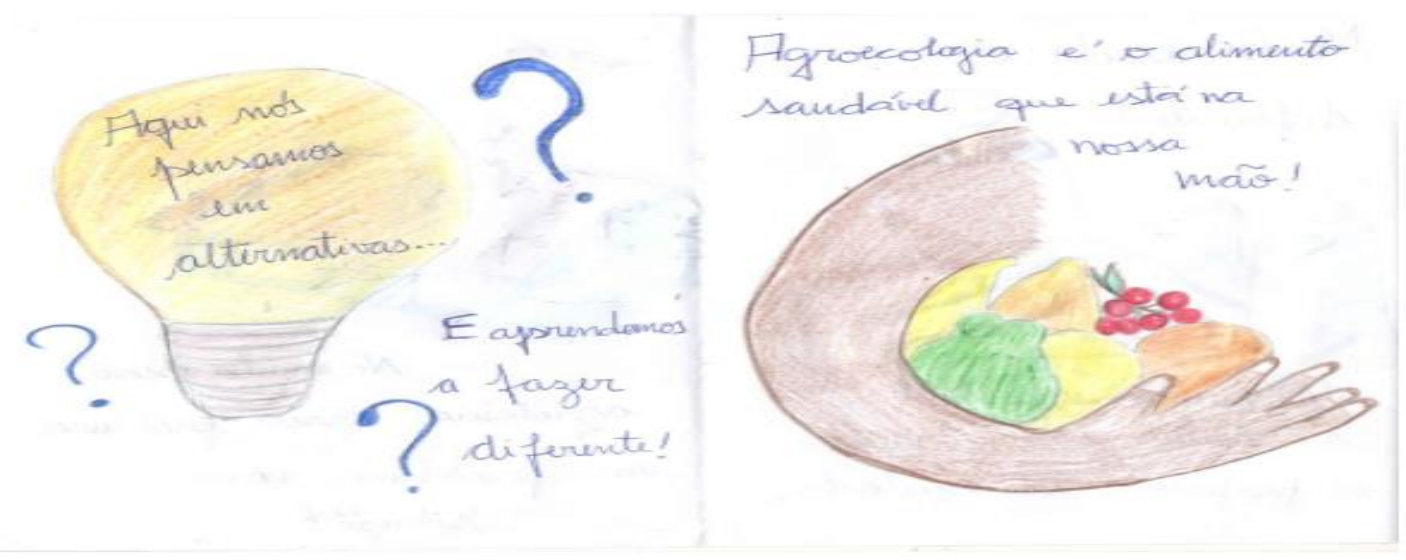

Figura 2 - Cartaz elaborado por um grupo de estudantes.

As atividades realizadas em sala de aula para a construção dos dados deste relato de experiência serviram de subsídio para a confecção de um fôlder informativo e educativo para distribuição aos estudantes e à comunidade escolar, sobre o tema agrotóxico e energias renováveis.

Assim, acredita-se na força da interação entre família, escola e sociedade visando a mudanças significativas. A Figura 3 destaca outra produção dos estudantes envolvidos neste trabalho, evidenciando a conscientização frente ao uso de agrotóxicos, bastante discutida na produção das verduras e legumes da horta da escola e de cada pequena propriedade rural. 

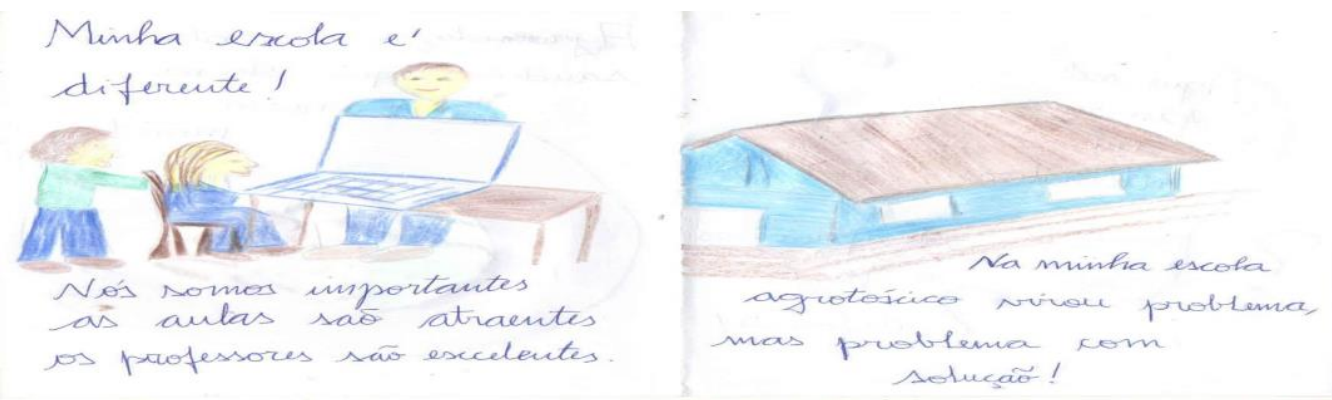

Figura 3 - Cartaz elaborado pelos estudantes, enfatizando a conscientização.

\section{CONCLUSÕES}

Uma das preocupações do ensino das Ciências, destacada por autores como Santos e Mortimer (2002) e Santos (2008), é promover um ensino democrático, crítico e contextualizado que vise à formação de cidadãos autônomos e que propicie a reflexão acerca das concepções de ciência e dos modos de desenvolvimento do conhecimento científico; em amplo domínio de análise, essa dinâmica busca tornar os estudantes aptos a participarem das decisões que envolvem a inovação científica e tecnológica.

O relato de experiência aqui apresentado buscou aproximações com a abordagem CTS para o Ensino de Ciências, mostrando a possibilidade da inserção de tal enfoque durante as aulas, tanto no Ensino Fundamental, quanto no Ensino Médio. O biodigestor construído pelos estudantes torna-se viável e importante para que se produza o adubo de origem orgânica e de qualidade - o biofertilizante - corretivo de acidez do solo. Outra alternativa viável com a construção do biodigestor é a geração de energia na forma de biogás, que contribui para que se amenizem as consequências das mudanças climáticas e do efeito estufa, levando em conta que o gás metano $\left(\mathrm{CH}_{4}\right)$ é mais nocivo que o gás carbônico $\left(\mathrm{CO}_{2}\right)$.

Os estudantes puderam perceber que o biogás produzido pelo biodigestor é gerado com aproveitamento dos resíduos encontrados no meio rural, podendo oportunizar economia visível e sustentabilidade ambiental, além de ser de fácil construção e com custo inicial baixo. Essa proposta pode ser reaproveitada pelos estudantes e suas famílias nas propriedades rurais, o que se converteria em sua utilização para a geração de biogás com destinos específicos das propriedades. 
Essa proposta vem ao encontro do que é salientado pelas Diretrizes Curriculares Nacionais Gerais da Educação Básica (BRASIL, 2013) ao afirmar que os professores precisam propiciar aos estudantes a vivência de situações práticas a partir das quais seja possível perceber a aplicabilidade dos conteúdos que são estudados na escola. É de vital importância que os estudantes compreendam que um fenômeno ou um problema pode ser descrito e analisado segundo diferentes perspectivas.

A interação dos estudantes e o envolvimento durante as atividade propostas é fator determinante para que alcancem os objetivos propostos pelo professor e despertem para o real sentido da aula, buscando alternativas sustentáveis para as pequenas propriedades rurais e dando sentido aos conteúdos aprendidos na escola.

Ao interagirem com a proposta e aceitarem o desafio, os estudantes foram agentes protagonistas de descobertas e mentores da construção do biodigestor, pois sugeriram, debateram, discutiram e construíram a experiência concreta. Para que a aprendizagem seja realmente significativa, é necessário que os estudantes estabeleçam relações entre os conteúdos das diversas áreas, modifiquem conceitos e concepções prévias e principalmente, encontrem aplicabilidade para os conteúdos estudados.

A análise da estrutura e da forma como a escola encontra-se organizada impõe, minimante, uma reflexão a respeito da necessidade de uma modificação na estrutura curricular, contemplando um enfoque que abra espaço para a CTS. Nesse sentido, é também imprescindível que professores tenham embasamento para contextualizar as inter-relações entre ciências e tecnologia e sociedade em suas aulas, promovendo uma articulação entre diferentes, mas harmônicos campos de saberes.

A experiência realizada no interior do RS e que serve de corpus para este relato permite-nos concluir, em última instância, sobre a incomensurável validade da apropriação dos moldes científicos para a contribuição com o conhecimento construído para a vida em sociedade. O legado dessa prática é o potencial de intervenção social crítica, por meio da reflexão, da sensibilização e da conscientização a respeito da influência da ciência e da tecnologia nas práticas das diversas esferas sociais. Mais que chamar representar uma produtiva possibilidade, a experiência aqui relatada, de fato, significa, convertendo a aplicação prática em construção de conhecimento. 


\section{REFERÊNCIAS}

BRASIL. Ministério da Educação, Secretaria de Educação Média e Tecnológica. Parâmetros Curriculares Nacionais: ensino médio. Brasília: Ministério da Educação, 1999. $360 \mathrm{p}$.

BRASIL. Secretaria de Educação Média e Tecnológica. PCNs+ ensino Médio: orientações educacionais complementares aos Parâmetros Curriculares Nacionais. Ciências da Natureza, Matemática e suas Tecnologias. Brasília: MEC, SEMTEC, 2002. $144 \mathrm{p}$.

BRASIL. Ministério da Educação. Secretaria de Educação Básica. Diretoria de Currículos e Educação Integral. Diretrizes Curriculares Nacionais Gerais da Educação Básica. Brasília: MEC, SEB, DICEI, 2013.

DELIZOICOV, Demétrio; ANGOTTI, José André Peres; PERNAMBUCO, Marta Maria C. A. Ensino de ciências: fundamentos e métodos. 3 ed. São Paulo: Cortez, 2009.

ESCOLA Estadual de Ensino Médio Marieta Tozzo. Projeto Político-Pedagógico (PPP). Itatiba do Sul, 2017.

FABRI, F.; SILVEIRA, R. M. C. F. O Ensino de Ciências nos anos iniciais e a abordagem CTS: elaborando estratégias de ensino. [S.1.]: Novas Edições Acadêmicas, 2015 .

HUNSCHE, S. Professor fazedor de currículos: desafios do estágio curricular supervisionado em Ensino de Física. 2010. Dissertação (Mestrado em Educação) Universidade Federal de Santa Maria, 2010.

NASCIMENTO, Tatiana Galieta; LINSINGEN, Irlan von. Articulações entre o enfoque CTS e a pedagogia de Paulo Freire como base para o ensino de ciências. Convergência, Toluca, v. 13, n. 42, setembro 2006, p. 95-116.

SANTOS, W. L. P.; MORTIMER, E. F. Uma Análise de Pressupostos Teóricos da Abordagem C-T-S (Ciência-Tecnologia-Sociedade) no Contexto da Educação Brasileira. Ensaio - Pesquisa em Educação em Ciências, Belo Horizonte, v. 2, n. 2, p. 133-162, dezembro 2002.

SANTOS, W. L. P. dos. Educação científica humanística em uma perspectiva freireana: resgatando a função do ensino de CTS. Alexandria Revista de Educação em Ciência e Tecnologia, v. 1, n. 1, p. 109-131, 2008. 
WARTHA, Edson José; SILVA, Erivaldo Lopes da; BEJARANO, Nelson Rui Ribas. Cotidiano e Contextualização no Ensino de Química. Química Nova na Escola, v. 35, n. 2, maio 2013, p. 84-91. 